\title{
Strength optimization of structural elements by means of optimal control
}

\author{
Dorota Jasinska ${ }^{1, *}$, and Leszek Mikulski ${ }^{1}$ \\ ${ }^{1}$ Institute of Structural Mechanics, Cracow University of Technology, Warszawska 24, 31-155 Krakow, Poland
}

\begin{abstract}
This paper investigates the optimal shaping of the web height of an I-section steel portal frame. The problem is formulated as a control theory task. From a mathematical perspective, the task involves solving the multipoint boundary value problem for the system of forty-three differential equations. The solution is compared to results obtained from the finite element software Abaqus.
\end{abstract}

\section{Introduction}

The optimal control theory, or more precisely one of its methods - the maximum principle, has been applied in this paper to the optimal shaping of a complex structural system. The optimization concerns the search for the shape of the cross-section under the adoption of various objective functions and constraints imposed by standards and technical regulations. Proper formulation of the optimization task, namely selecting an appropriate objective function, control variables, and necessary constraints, is critical, as an inappropriate formulation may negate all of the advantages that were obtained from optimization.

In particular, this article studies the shape optimization of the portal steel frame, more specifically the optimal shaping of the web of the frame I-section at fixed flange dimensions, under the action of various prescribed external loads. Formulating the problem within the framework of the control theory [1] enables a fast and precise method for obtaining the optimal solution. The issue of the frame cross-section shaping was explored in [2] [3], [4], and [5], where the optimization of portal frames with a side aisle by gradient iterative methods combined with the finite element analysis was studied. In [6] half of the frame was shaped under action of both symmetric and antisymmetric loads.

\section{Description of the optimization task}

The subject of this optimization is a steel portal Isection frame constituting the repetitive load bearing element of a storage hall. The dimensions and the static diagram of the frame are presented in Fig. 1. The state variables are defined as: $u_{i}$ - normal displacement, $\phi_{i}$ deflection angle, $M_{i}$ - bending moment, $Q_{i}$-transverse force, $N_{i}$ - longitudinal force, $w_{i}$ - tangential displacement, $v$-frame volume, where $i \in(1,7)$ represents consecutive load states.

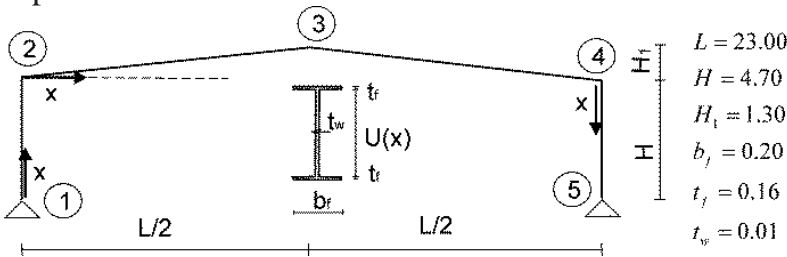

Fig. 1. Dimensions $[\mathrm{m}]$ and static diagram of the frame

\subsection{Static scheme}

The frame consists of two columns and two equal-pitch rafters. Both the apex connection and the rafter - column connections are designed as rigid joints. Column base connections are modeled as pin joints.

\subsection{Applied loads}

The following elementary loads cases were taken into account while developing the state equations describing the structure:

1. Maximum dead load $g_{\max }=A \cdot \gamma_{s} \cdot 1.35 \cdot 0.85=1.15 \cdot A \cdot \gamma_{s}$

2. Maximum roofing dead load, regarded as a constant continuous load imposed on the rafters $g_{r \max }=1.913 \frac{\mathrm{kN}}{\mathrm{m}}$

3. Minimum frame dead load $g_{\min }=A \cdot \gamma_{s} \cdot 0.85$

4. Minimum roofing dead load $g_{r \min }=1.517 \frac{\mathrm{kN}}{\mathrm{m}}$

5. Snow load applied to the rafters $S=7.391 \frac{\mathrm{kN}}{\mathrm{m}}$

6. Wind load: wind from the left: pressure-left column $w_{l c}^{\text {left }}=1.97 \frac{\mathrm{kN}}{\mathrm{m}}$, suction-left rafter $w_{l r}^{\text {left }}=-2.51 \frac{\mathrm{kN}}{\mathrm{m}}$, suction- right rafter $w_{r r}^{l e f t}=-1.13 \frac{\mathrm{kN}}{\mathrm{m}}$, suction -right 
column $w_{r c}^{\text {left }}=-1.12 \frac{\mathrm{kN}}{\mathrm{m}}$

7. Wind load - wind from the right (by analogy):

$$
\begin{aligned}
& w_{l c}^{\text {right }}=-1.12 \frac{\mathrm{kN}}{\mathrm{m}}, w_{l r}^{\text {right }}=-1.13 \frac{\mathrm{kN}}{\mathrm{m}}, w_{r r}^{\text {right }}=-2.51 \frac{\mathrm{kN}}{\mathrm{m}}, \\
& w_{r c}^{\text {right }}=1.97 \frac{\mathrm{kN}}{\mathrm{m}}
\end{aligned}
$$

\subsection{Primary system of equations}

The web height of the I-section is assumed to be the decision variable in the considered problem. The independent variable is measured from the base of the left column along its axis to the column-rafter connection, then horizontally along the rafters, and finally vertically to the base of the right column (Fig.1). Four integration ranges (characteristic intervals) are assumed: the left column (1-2), the left rafter(2-3), the right rafter(3-4), and the right column(4-5) (see Fig.1).

The state equations are defined in the initial configuration for columns and in the deformed configuration for rafters. In consecutive characteristic intervals they take the form:

for the left column;

$$
\begin{aligned}
& u^{\prime}=\phi, \phi^{\prime}=\frac{M}{E I_{c}}, M^{\prime}=Q \\
& Q^{\prime}=-q_{t}, N^{\prime}=-q_{n}, w^{\prime}=0
\end{aligned}
$$

for the left rafter:

$$
\begin{aligned}
& u^{\prime}=\frac{\phi}{\cos (\alpha+\phi)}, \phi^{\prime}=\frac{M}{E I_{r} \cos (\alpha+\phi)}, \\
& M^{\prime}=\frac{Q}{\cos (\alpha+\phi)}, Q^{\prime}=-\frac{q_{t}}{\cos (\alpha+\phi)}, \\
& N^{\prime}=\frac{q_{n}}{\cos (\alpha+\phi)}, w^{\prime}=0
\end{aligned}
$$

for the right rafter:

$$
\begin{aligned}
& u^{\prime}=\frac{\phi}{\cos (\alpha+\phi)}, \phi^{\prime}=\frac{M}{E I_{r} \cos (\alpha+\phi)}, \\
& M^{\prime}=\frac{Q}{\cos (\alpha+\phi)}, Q^{\prime}=-\frac{q_{t}}{\cos (\alpha+\phi)}, \\
& N^{\prime}=-\frac{q_{n}}{\cos (\alpha+\phi)}, w^{\prime}=0
\end{aligned}
$$

for the right column :

$$
\begin{aligned}
& u^{\prime}=\phi, \phi^{\prime}=\frac{M}{E I_{c}}, M^{\prime}=Q \\
& Q^{\prime}=-q_{t}, N^{\prime}=-q_{n}, w^{\prime}=0
\end{aligned}
$$

In formulas (1)-(4): $q_{t}$ is the continuous load normal to the axis, $q_{n}$ - load tangent to the axis and $\alpha$ - rafter pitch angle.

The integration was performed over four intervals: $1^{\text {st }}-$ along the left column $x \in(0.0,4.7), 2^{\text {nd }}-$ the left rafter $x \in(4.7,16.2), 3^{\text {rd }}$-the right rafter $x \in(16.2,27.7)$, and $4^{\text {th }}$ the right column $x \in(27.7,32.4)$. State variables defined for the subsequent load are compiled in Table 1.

Table 1. State variables in consecutive load states

\begin{tabular}{|l|c|l|l|l|l|l|}
\hline & $u$ & $\phi$ & $M$ & $Q$ & $N$ & $w$ \\
\hline Load case 1 & $y_{1}$ & $y_{2}$ & $y_{3}$ & $y_{4}$ & $y_{5}$ & $y_{6}$ \\
\hline Load case 2 & $y_{7}$ & $y_{8}$ & $y_{9}$ & $y_{10}$ & $y_{11}$ & $y_{12}$ \\
\hline Load case 3 & $y_{13}$ & $y_{14}$ & $y_{15}$ & $y_{16}$ & $y_{17}$ & $y_{18}$ \\
\hline Load case 4 & $y_{19}$ & $y_{20}$ & $y_{21}$ & $y_{22}$ & $y_{23}$ & $y_{24}$ \\
\hline Load case 5 & $y_{25}$ & $y_{26}$ & $y_{27}$ & $y_{28}$ & $y_{29}$ & $y_{30}$ \\
\hline Load case 6 & $y_{31}$ & $y_{32}$ & $y_{33}$ & $y_{34}$ & $y_{35}$ & $y_{36}$ \\
\hline Load case 7 & $y_{37}$ & $y_{38}$ & $y_{39}$ & $y_{40}$ & $y_{41}$ & $y_{42}$ \\
\hline volume & $y_{43}$ & & & & & \\
\hline
\end{tabular}

For every characteristic interval (each phase) and assumed loads, one can formulate the set of 43 first order differential equations. For instance for the left rafter $(x \in(4.70,16.20))$ :

frame dead load (max)

$$
\begin{aligned}
& y_{1}{ }^{\prime}=\frac{y_{2}}{\cos \left(\alpha+y_{2}\right)}, \quad y_{2}{ }^{\prime}=\frac{y_{3}}{E I_{r} \cos \left(\alpha+y_{2}\right)}, \\
& y_{3}{ }^{\prime}=\frac{y_{4}}{\cos \left(\alpha+y_{2}\right)}, \quad y_{4}{ }^{\prime}=-A_{r} \gamma_{s} \cdot 1.15, \\
& y_{5}{ }^{\prime}=\frac{A_{r} \gamma_{s} \cdot 1.15 \cdot \sin \left(\alpha+y_{2}\right)}{\cos \left(\alpha+y_{2}\right)}, \quad y_{6}{ }^{\prime}=0
\end{aligned}
$$

roofing dead load (max)

$$
\begin{aligned}
& y_{7}{ }^{\prime}=\frac{y_{8}}{\cos \left(\alpha+y_{8}\right)}, \quad y_{8}{ }^{\prime}=\frac{y_{9}}{E I_{r} \cos \left(\alpha+y_{8}\right)}, \\
& y_{9}{ }^{\prime}=\frac{y_{10}}{\cos \left(\alpha+y_{8}\right)}, \quad y_{10}{ }^{\prime}=-g_{r \text { max }}, \\
& y_{11}{ }^{\prime}=\frac{g_{r \max } \cdot \sin \left(\alpha+y_{8}\right)}{\cos \left(\alpha+y_{8}\right)}, \quad y_{12}{ }^{\prime}=0
\end{aligned}
$$

frame dead load (min)

$$
\begin{aligned}
& y_{13}{ }^{\prime}=\frac{y_{14}}{\cos \left(\alpha+y_{14}\right)}, \quad y_{14}{ }^{\prime}=\frac{y_{15}}{E I_{r} \cos \left(\alpha+y_{14}\right)}, \\
& y_{15}{ }^{\prime}=\frac{y_{16}}{\cos \left(\alpha+y_{14}\right)}, \quad y_{16}{ }^{\prime}=-A_{r} \gamma_{s} \cdot 0.85, \\
& y_{17}{ }^{\prime}=\frac{A_{r} \gamma_{s} \cdot 0.85 \cdot \sin \left(\alpha+y_{14}\right)}{\cos \left(\alpha+y_{14}\right)}, \quad y_{18}{ }^{\prime}=0
\end{aligned}
$$

roofing dead load ( $\min )$

$$
\begin{aligned}
& y_{19}{ }^{\prime}=\frac{y_{20}}{\cos \left(\alpha+y_{20}\right)}, \quad y_{20}{ }^{\prime}=\frac{y_{21}}{E I_{r} \cos \left(\alpha+y_{20}\right)}, \\
& y_{21}{ }^{\prime}=\frac{y_{22}}{\cos \left(\alpha+y_{20}\right)}, \quad y_{22}{ }^{\prime}=-g_{r \min }, \\
& y_{23}{ }^{\prime}=\frac{g_{r \min } \cdot \sin \left(\alpha+y_{20}\right)}{\cos \left(\alpha+y_{20}\right)}, \quad y_{24}{ }^{\prime}=0
\end{aligned}
$$

snow load 
$y_{25}{ }^{\prime}=\frac{y_{26}}{\cos \left(\alpha+y_{26}\right)}, \quad y_{26}{ }^{\prime}=\frac{y_{27}}{E I_{r} \cos \left(\alpha+y_{26}\right)}$,

$y_{27}{ }^{\prime}=\frac{y_{28}}{\cos \left(\alpha+y_{26}\right)}, \quad y_{28}{ }^{\prime}=-S$,

$y_{29}{ }^{\prime}=\frac{S \cdot \sin \left(\alpha+y_{26}\right)}{\cos \left(\alpha+y_{26}\right)}, \quad y_{30}{ }^{\prime}=0$

wind from the left

$y_{31}{ }^{\prime}=\frac{y_{32}}{\cos \left(\alpha+y_{32}\right)}, \quad y_{32}{ }^{\prime}=\frac{y_{33}}{E I_{r} \cos \left(\alpha+y_{32}\right)}$,

$y_{33}{ }^{\prime}=\frac{y_{34}}{\cos \left(\alpha+y_{32}\right)}, y_{34}{ }^{\prime}=\frac{-w_{l r}^{l r f t}}{\cos \left(\alpha+y_{32}\right)}, y_{35}{ }^{\prime}=0, y_{36}{ }^{\prime}=0$

wind from the right

$y_{37}{ }^{\prime}=\frac{y_{38}}{\cos \left(\alpha+y_{38}\right)}, \quad y_{38}{ }^{\prime}=\frac{y_{39}}{E I_{r} \cos \left(\alpha+y_{38}\right)}$,

$y_{39}{ }^{\prime}=\frac{y_{40}}{\cos \left(\alpha+y_{38}\right)}, y_{40}{ }^{\prime}=\frac{-w_{l r}^{r i g h t}}{\cos \left(\alpha+y_{38}\right)}, y_{41}{ }^{\prime}=0, y_{42}{ }^{\prime}=0$

$$
y_{43}{ }^{\prime}=A_{r}
$$

where:

$$
\begin{aligned}
& A_{r}=2 b_{f} t_{f}+U(x) t_{w}, \\
& I_{r}=2\left(\frac{b_{f} t_{f}^{3}}{12}+b_{f} t_{f}\left(\frac{U(x)+t_{f}}{2}\right)^{2}\right)+\frac{t_{w} U(x)^{3}}{12} .
\end{aligned}
$$

The remaining state equations (for the right rafter and both columns) have a similar form and have not been listed.

\subsection{Boundary and internal point conditions}

Exemplary initial-boundary conditions together with internal point conditions concerning characteristic points for load cases 1 and 2 are listed in table 2 .

Table 2. Boundary conditions and internal point conditionsload cases 1 and 2

\begin{tabular}{|l|l|l|l|l|l|l|}
\hline \multicolumn{2}{|l|}{ Characteristic points } & 1 & 2 & 3 & 4 & 5 \\
\hline \multirow{5}{*}{ Load case 1 } & $y_{1}$ & 0 & & & & 0 \\
\hline & $y_{2}$ & & $\mathrm{C}$ & $\mathrm{C}$ & $\mathrm{C}$ & \\
\hline & $y_{3}$ & 0 & $\mathrm{C}$ & $\mathrm{C}$ & $\mathrm{C}$ & 0 \\
\hline & $y_{4}$ & & & & & \\
\hline & $y_{5}$ & & & & & \\
\hline & $y_{6}$ & 0 & & & & 0 \\
\hline \multirow{5}{*}{ Load case 2 } & $y_{7}$ & 0 & & & & 0 \\
\hline & $y_{8}$ & & $\mathrm{C}$ & $\mathrm{C}$ & $\mathrm{C}$ & \\
\hline & $y_{9}$ & 0 & $\mathrm{C}$ & $\mathrm{C}$ & $\mathrm{C}$ & 0 \\
\hline & $y_{10}$ & & & & & \\
\hline & $y_{11}$ & & & & & \\
\hline & $y_{12}$ & 0 & & & & 0 \\
\hline
\end{tabular}

Equations describing the frame in every load case must be complemented with 84 implicit conditions in characteristic points 2, 3, and 4 (frame nodes force equilibrium conditions and displacement compatibility). Those conditions exemplary in characteristic point 2 $(x=4.7)$ in the first load case take the form [7]

$$
\begin{aligned}
& -y_{4}\left(4.7^{-}\right)+y_{4}\left(4.7^{+}\right) \sin \left(\alpha+y_{2}\left(4.7^{+}\right)\right) \\
& +y_{5}\left(4.7^{+}\right) \cos \left(\alpha+y_{2}\left(4.7^{+}\right)\right)=0 \\
& -y_{5}\left(4.7^{-}\right)+y_{4}\left(4.7^{+} 0\right) \cos \left(\alpha+y_{2}\left(4.7^{+}\right)\right) \\
& +y_{4}\left(4.7^{+}\right) \sin \left(\alpha+y_{2}\left(4.7^{+}\right)\right)=0 \\
& y_{1}\left(4.7^{-}\right)-y_{1}\left(4.7^{+}\right) \sin \left(\alpha+y_{2}\left(4.7^{+}\right)\right) \\
& +y_{6}\left(4.7^{+}\right) \cos \left(\alpha+y_{2}\left(4.7^{+}\right)\right)=0 \\
& y_{6}\left(4.7^{-}\right)-y_{1}\left(4.7^{+} 0\right) \cos \left(\alpha+y_{2}\left(4.7^{+}\right)\right) \\
& -y_{6}\left(4.7^{+}\right) \sin \left(\alpha+y_{2}\left(4.7^{+}\right)\right)=0
\end{aligned}
$$

\section{Load combinations}

Table 3 details the twelve load combinations of the seven load cases that were accounted for in the optimization procedure.

\subsection{Normal stresses and displacements}

Normal stresses for the particular load combination are expressed as:

$$
\begin{aligned}
& \sigma_{1}^{I}=\frac{\left|y_{3}+y_{9}\right| \cdot Z}{I}+\frac{\left|y_{5}+y_{11}\right|}{A}, \\
& \sigma_{2}^{I}=\frac{\left|y_{3}+y_{9}+y_{27}\right| \cdot Z}{I}+\frac{\left|y_{5}+y_{11}+y_{29}\right|}{A}, \\
& \sigma_{3}^{I}=\frac{\left|y_{3}+y_{9}+y_{27}+y_{33}\right| \cdot Z}{I}+\frac{\left|y_{5}+y_{11}+y_{29}+y_{35}\right|}{A}, \\
& \sigma_{4}^{I}=\frac{\left|y_{3}+y_{9}+y_{27}+y_{39}\right| \cdot Z}{I}+\frac{\left|y_{5}+y_{11}+y_{29}+y_{41}\right|}{A}, \\
& \sigma_{5}^{I}=\frac{\left|y_{3}+y_{9}+y_{33}\right| \cdot Z}{I}+\frac{\left|y_{5}+y_{11}+y_{35}\right|}{A}, \\
& \sigma_{6}^{I}=\frac{\left|y_{3}+y_{9}+y_{39}\right| \cdot Z}{I}+\frac{\left|y_{5}+y_{11}+y_{41}\right|}{A}, \\
& \sigma_{7}^{I}=\frac{\left|y_{15}+y_{21}\right| \cdot Z}{I}+\frac{\left|y_{17}+y_{23}\right|}{A}, \frac{\left|y_{15}+y_{21}+y_{27}\right| \cdot Z}{I}+\frac{\left|y_{17}+y_{23}+y_{29}\right|}{A}, \\
& \sigma_{8}^{I}=\frac{\left|y_{15}+y_{21}+y_{27}+y_{33}\right| \cdot Z}{I}+\frac{\left|y_{17}+y_{23}+y_{29}+y_{35}\right|}{A}, \\
& \sigma_{9}^{I}=\frac{\left|y_{15}+y_{21}+y_{39}\right| \cdot Z}{I}+\frac{\left|y_{17}+y_{23}+y_{41}\right|}{A} \\
& \sigma_{10}^{I}=\frac{\left|y_{15}+y_{21}+y_{27}+y_{39}\right| \cdot Z}{I}+\frac{\left|y_{17}+y_{23}+y_{29}+y_{41}\right|}{A}, \\
& \left.\sigma_{15}^{I}\right) \\
& I y_{21} \mid \cdot Z \\
& I y_{17}+y_{23}+y_{35} \mid \\
& A
\end{aligned}
$$


The second order effects (rafter warping and column buckling) are not included in the model.

Normal displacements for adopted load combinations take the form:

$$
\begin{gathered}
Y_{1}=y_{1}+y_{7}, Y_{2}=y_{1}+y_{7}+y_{25}, Y_{3}=y_{1}+y_{7}+y_{25}+y_{31}, \\
Y_{4}=y_{1}+y_{7}+y_{25}+y_{37}, Y_{5}=y_{1}+y_{7}+y_{31}, \\
Y_{6}=y_{1}+y_{7}+y_{37}, Y_{7}=y_{13}+y_{19}, Y_{8}=y_{13}+y_{19}+y_{25}, \\
Y_{9}=y_{13}+y_{19}+y_{25}+y_{31}, Y_{10}=y_{13}+y_{19}+y_{25}+y_{37}, \\
Y_{11}=y_{13}+y_{19}+y_{31}, Y_{12}=y_{13}+y_{19}+y_{37} \\
Y=\max _{k=1,12}\left(\left|Y_{k}\right|\right)
\end{gathered}
$$

The secondary conditions in the optimization problem can be written as:

$$
\begin{aligned}
& g_{1}=f_{d}-\sigma \geq 0, \\
& g_{2}=W_{d}-W \geq 0, \\
& g_{3}=Y_{d}-Y \geq 0,
\end{aligned}
$$

where: $f_{d}=215 M P a, W_{d}=0.023 \mathrm{~m}$ and

$Y_{d}=\frac{L}{115}=0.2 m$ (Fig. 1$)$.

The condition $g_{1}=0$ describes the ultimate limit state (ULS) and restricts the maximum value of normal stresses, whereas the prerequisites $g_{2}=0$ and $g_{3}=0$ (serviceability limit state- SLS ) restrict the horizontal displacements $W$, and rafter deflection $Y$ in every design situation. Moreover, limitations are placed on the control variable $U(x) \in[0.25,0.55] \mathrm{m}$.

Table 3. Combinations of load states

\begin{tabular}{|l|l|c|c|c|c|c|c|c|c|c|c|c|c|}
\hline & & 1 & 2 & 3 & 4 & 5 & 6 & 7 & 8 & 9 & 10 & 11 & 12 \\
\hline 1 & $\begin{array}{l}\text { DL } \\
\max \end{array}$ & $\mathrm{x}$ & $\mathrm{x}$ & $\mathrm{x}$ & $\mathrm{x}$ & $\mathrm{x}$ & $\mathrm{x}$ & & & & & & \\
\hline 2 & $\mathrm{R} \mathrm{max}$ & $\mathrm{x}$ & $\mathrm{x}$ & $\mathrm{x}$ & $\mathrm{x}$ & $\mathrm{x}$ & $\mathrm{x}$ & & & & & & \\
\hline 3 & $\begin{array}{l}\text { DL } \\
\min \end{array}$ & & & & & & & $\mathrm{x}$ & $\mathrm{x}$ & $\mathrm{x}$ & $\mathrm{x}$ & $\mathrm{x}$ & $\mathrm{x}$ \\
\hline 4 & R min & & & & & & & $\mathrm{x}$ & $\mathrm{x}$ & $\mathrm{x}$ & $\mathrm{x}$ & $\mathrm{x}$ & $\mathrm{x}$ \\
\hline 5 & snow & & $\mathrm{x}$ & $\mathrm{x}$ & $\mathrm{x}$ & & & & $\mathrm{x}$ & $\mathrm{x}$ & $\mathrm{x}$ & & \\
\hline 6 & WL I & & & $\mathrm{x}$ & & $\mathrm{x}$ & & & & $\mathrm{x}$ & & $\mathrm{x}$ & \\
\hline 7 & WL II & & & & $\mathrm{x}$ & & $\mathrm{x}$ & & & & $\mathrm{x}$ & & $\mathrm{x}$ \\
\hline
\end{tabular}

\section{Objective function}

The volume of the steel frame is assumed as the objective function in the form of the functional

$$
J(U)=\int_{0}^{4.7} A_{c} d x+\int_{4.7}^{27.7} A_{r} d x+\int_{27.7}^{32.4} A_{c} d x
$$

The functional (12) is then replaced by the suitable differential equation

$$
y_{43}{ }^{\prime}=A_{r}, \quad y_{43}(0)=0
$$

Finally, the problem of the optimal shaping of the I section web height $U(x)$ for the steel portal frame, in the framework of the control theory, takes the form

$$
\min _{u} y_{43}
$$

One should determine a control variable $U(x)$ minimizing the functional (12), under restrictions in the form of state equations $(5,6)$, with initial-boundary conditions, internal point conditions (tab. 2), local equilibrium conditions, and limits for maximal stresses (9) and deflections (10). Based on the minimum principle, the necessary optimization conditions were compiled, forming the differential-algebraic boundary value problem. Using the Hamilton function the above conditions can be expressed as

$$
y^{\prime}=f(x, y, U), \quad \lambda^{\prime}=-\frac{\partial H}{\partial y}, \quad \frac{\partial H}{\partial U}=0 .
$$

These conditions are automatically compiled in the numerical program dircol-2 with the use of appropriate subroutines describing the problem [8]. Finding the proper control structure (course of the control variable) is possible only after the solution of the boundary-value problem is found, as the optimal control theory does not provide significant information on the structure. For the considered problem the following solution structure proved to be appropriate

$$
U(x)=\left\{\begin{array}{lll}
U_{1} & x \in(0,2.35) & \\
U_{o p t} & x \in(2.35,7.0) & g_{1}=0 \text { for } x \in(2.35,6.42) \\
U_{1} & x \in(7.0,14.18) & \\
U_{o p t} & x \in(14.18,19.36) & g_{3}=0 \text { for } x=4.7 \\
U_{1} & x \in(19.36,25.4) & \\
U_{o p t} & x \in(25.4,30.38) & g_{1}=0 \text { for } x \in(25.4,28.7) \\
U_{1} & x \in(30.38,32.4) &
\end{array}\right.
$$

\section{Results of numerical analysis}

The final objective of the study is to determine the course of the control variable $U(x)$ - the height of the Isection web fulfilling the necessary optimization conditions and assumed restrictions. The resultant trajectory is depicted in Fig. 2.

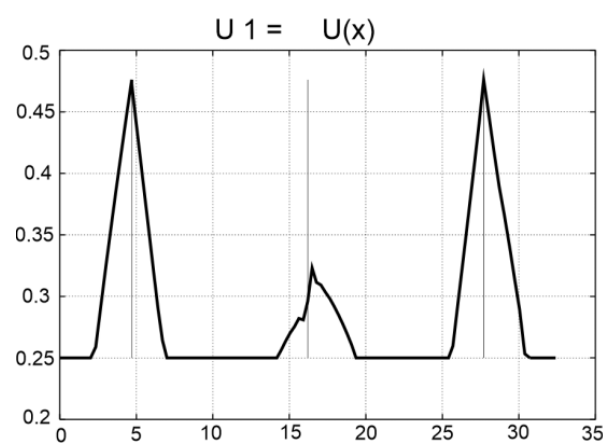

Fig. 2 Control variable- the optimal height of the frame I section web. 
The complete solution of the numerically formulated optimization problem contains graphs of all state variables $y_{i}$ and conjugate functions $\lambda_{i}$, enabling a deeper insight into the optimal solution structure. The exemplary trajectories of the state variables for the second load case $\left(y_{6}-y_{12}\right)$ are presented in Figure 3. In the discussed example almost all imposed constrains are active:, rafter deflection and horizontal displacement limit are active pointwise, whereas the stress constraint and minimal geometrical restriction on the web height are active in the intervals (Eq. 16, Fig.2, Tab. 4). Only the maximum allowable web height limit remains inactive.
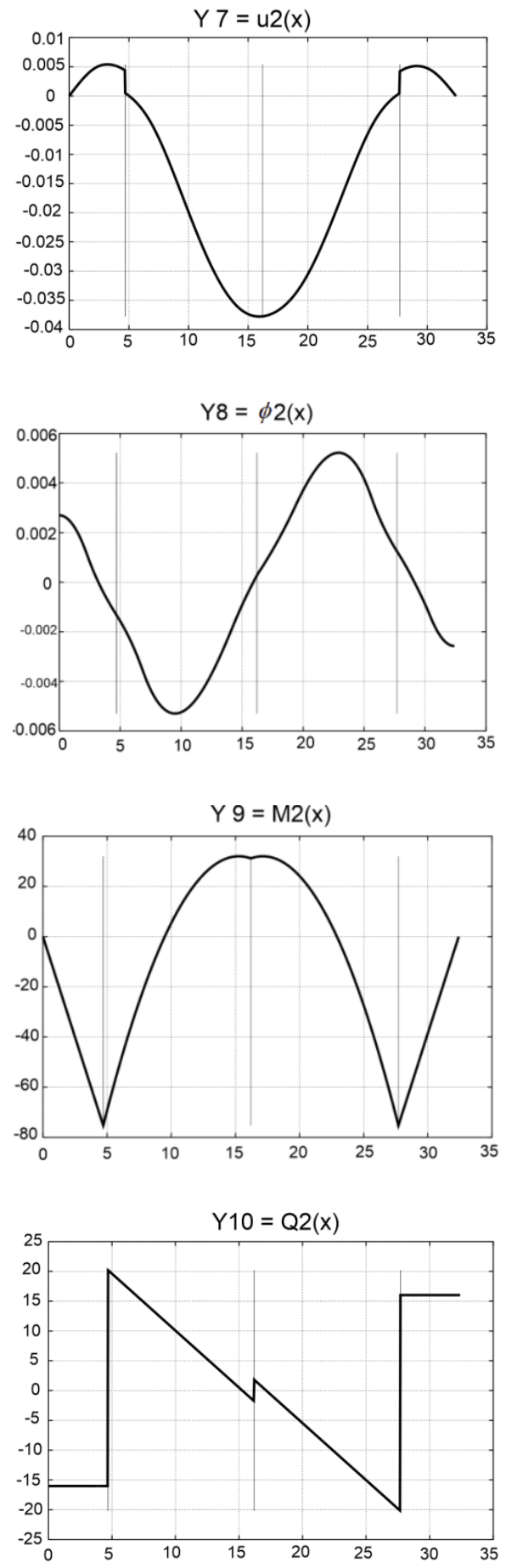
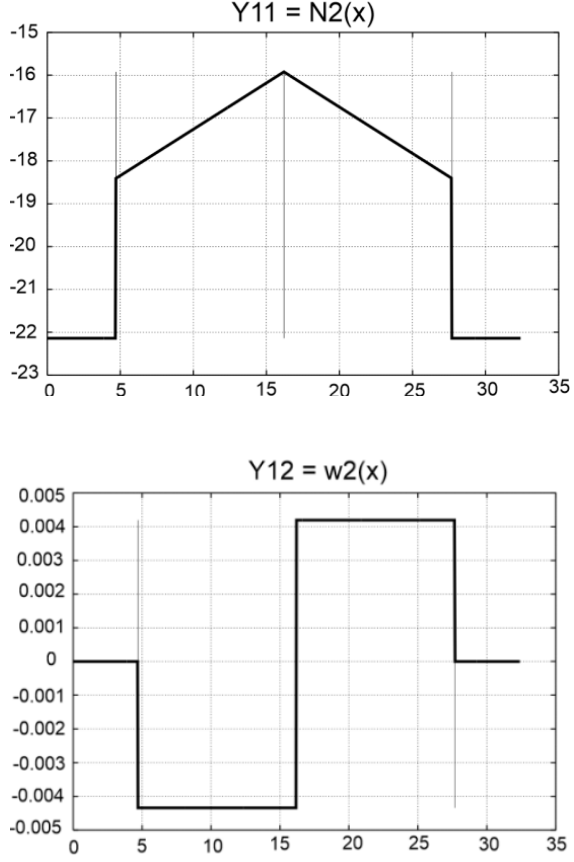

Fig. 3 State variables $y_{7}-y_{12}$ referring to the second load case (described in Tab.1)

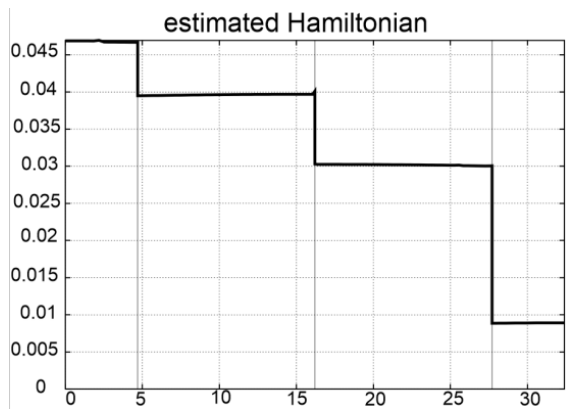

Fig. 4 The Hamilton function

The obtained course of variability of the web height is not fully symmetric (see Fig.2). This effect can be attributed to the fact that the minimum Pontriagin principle allows for the finding of a solution that fulfils all necessary optimality conditions, without guaranteeing that it constitutes the only or the global minimum. The optimal solution is obtained for the independent variable running from left to right (Fig.1). If this direction is switched, the control variable will be its mirror image. The final symmetrised optimal sulution is presented in Fig.5.

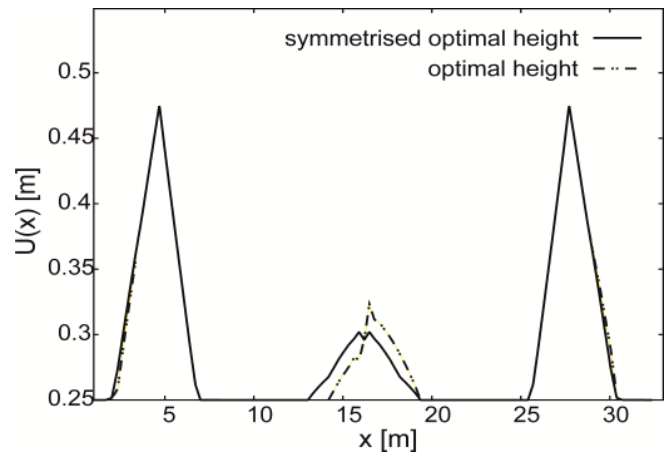

Fig. 5 Symmetrised web height 
Table 4. Comparison of optimized and non-optimized frames

\begin{tabular}{|l|l|l|l|l|}
\hline Frame type & $\begin{array}{l}\text { Frame } \\
\text { volume } \\
{\left[\mathrm{m}^{3}\right]}\end{array}$ & $\begin{array}{l}\text { ULS } \\
g_{1}\end{array}$ & $\begin{array}{l}\text { SLS } \\
g_{2}\end{array}$ & $\begin{array}{l}\text { SLS } \\
g_{3}\end{array}$ \\
\hline $\begin{array}{l}\text { optimal web } \\
\text { height } U(x)\end{array}$ & 0.302 & $\begin{array}{l}\text { interval } \\
\text { active }\end{array}$ & $\begin{array}{l}\text { pointwise } \\
\text { active }\end{array}$ & $\begin{array}{l}\text { pointwise } \\
\text { active }\end{array}$ \\
\hline $\begin{array}{l}\text { constant web } \\
\text { height } 0.55 \mathrm{~m}\end{array}$ & 0.387 & inactive & inactive & inactive \\
\hline $\begin{array}{l}\text { constant web } \\
\text { height } 0.45 \mathrm{~m}\end{array}$ & 0.355 & $\begin{array}{l}\text { pointwise } \\
\text { active }\end{array}$ & inactive & inactive \\
\hline
\end{tabular}

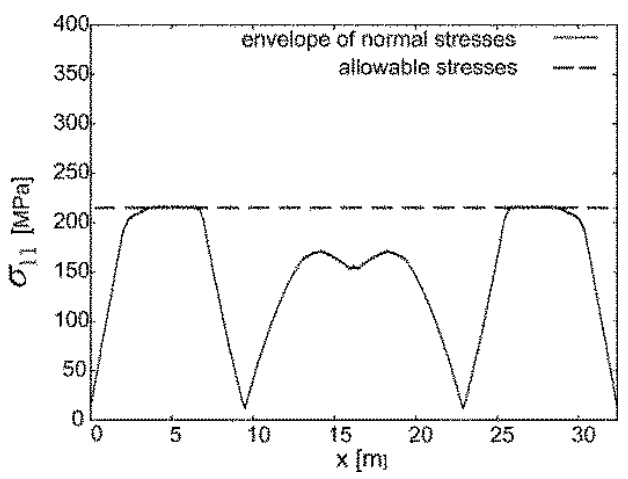

Fig. 6 Envelope of normal stresses

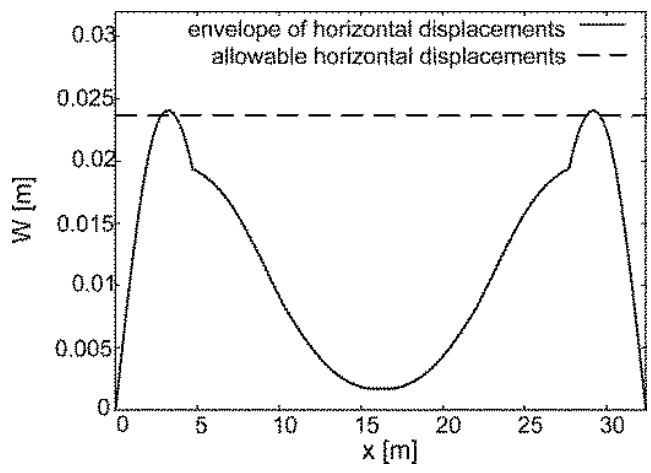

Fig. 7 Envelope of horizontal displacements

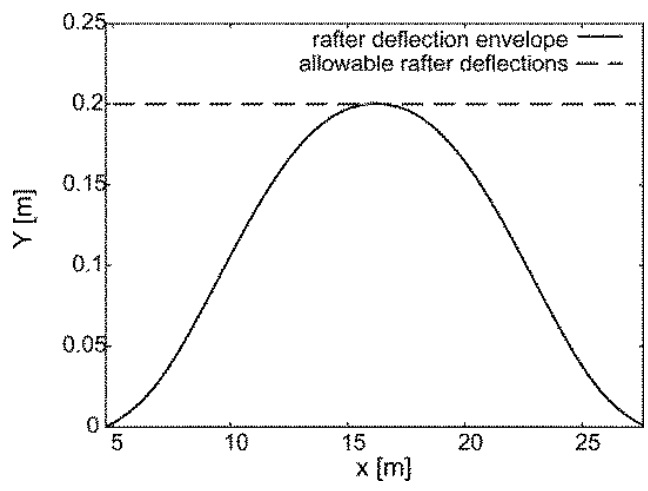

Fig. 8 Envelope of rafter deflections

The load carrying capacity and maximal displacements of the symmetrised optimized frame are compared to the results for two similar frames of constant I section web heights, subjected subsequently to 12 load combinations listed in Table 1. These calculations were performed in FEM code Abaqus. The volumes of the frames are collated in Table 4. It can be noted, that the maximal mass reduction due to optimal shaping is $22 \%$. The envelopes of normal stresses, horizontal displacements and rafter deflections, presented in Figures 6, 7, and 8, confirm that the resultant optimal frame meets all predetermined design conditions.

\section{Conclusions}

The task of the optimal shaping of the steel portal frame presented in this paper fallows the framework of the optimal control theory, based on the maximum principle. The structure of this optimization allowed for a simultaneous introduction of all load states into a mathematical model, which is crucial because of numerous and complex design conditions incorporated in the task.

The numerical solution of the optimization problem meets all necessary optimality conditions. The Hamilton function (Fig.4) is piecewise constant, with discontinuities at characteristic points. The trajectories of the state and adjoint variables meet the transversality conditions, emphasizing the correctness of the obtained results. The results of the performed analysis confirm that the theory of optimal control in combination with the FEM computations can be successfully applied to structure optimal shaping. The optimal solutions can be used in practical applications or at, at a minimum, a measure of correct design.

Acknowledgment

The research was supported by Pl-grid Infrastructure.

\section{References}

1. H.J.Pesch, Contr.Cybern.,23, Nos.1-2, 7-60, (1994)

2. J.Farkas, K. Jarmai, Optimum design of steel structures, Springer Verlag Berlin Heidenberg (2013)

3. H. Laskowski, L.Mikulski, Pomiary, Automatyka, Kontrola, 6, 346-351, (2009)

4. D. Kropiowska, Selected problems of the optimal design of bar systems within the formal structure of the minimum principle, CUT Publishing House, Cracow (2016)

5. S. Sobczyk, L.Mikulski, Pomiary Automatyka Kontrola, 11, 1060-1064, (2014)

6. H. Laskowski, Techn. Trans.,6,119-134,(2017)

7. O. von Stryk, Numerical hybrid optimal control and related topics, TU Munchen, Habilitationsschrift, (2002)

8. O. von Stryk, Users guide. A direct collocation method for the numerical solution of optimal control problems, TU Darmstadt, SIM, Version 2.1,(2002) 